\title{
The detection and stability of the SARS-CoV-2 RNA biomarkers in wastewater influent in Helsinki, Finland
}

\section{Hokajärvi, Anna-Maria}

2021-05-20

Hokajärvi , A-M , Rytkönen , A , Tiwari , A , Kauppinen , A , Oikarinen , S , Lehto , K-M , Kankaanpää , A , Gunnar , T , Al-Hello , H , Blomqvist , S , Miettinen , I T, Savolainen-Kopra , C \& Pitkänen , T 2021 , ' The detection and stability of the SARS-CoV-2 RNA biomarkers in wastewater influent in Helsinki, Finland ' , The Science of the Total Environment , vol. 770 , 145274 . https://doi.org/10.1016/j.scitotenv.2021.145274

http://hdl.handle.net/10138/329302

https://doi.org/10.1016/j.scitotenv.2021.145274

cc_by_nc_nd

publishedVersion

Downloaded from Helda, University of Helsinki institutional repository.

This is an electronic reprint of the original article.

This reprint may differ from the original in pagination and typographic detail.

Please cite the original version. 


\title{
The detection and stability of the SARS-CoV-2 RNA biomarkers in wastewater influent in Helsinki, Finland
}

\author{
Anna-Maria Hokajärvi a ${ }^{\text {a }}$ Annastiina Rytkönen ${ }^{\mathrm{a}}$, Ananda Tiwari ${ }^{\mathrm{a}}$, Ari Kauppinen ${ }^{\mathrm{a}, 1}$, Sami Oikarinen ${ }^{\mathrm{b}}$, \\ Kirsi-Maarit Lehto ${ }^{\mathrm{b}}$, Aino Kankaanpää ${ }^{\mathrm{c}}$, Teemu Gunnar ${ }^{\mathrm{c}}$, Haider Al-Hello ${ }^{\mathrm{d}}$, Soile Blomqvist ${ }^{\mathrm{d}}$, \\ Ilkka T. Miettinen ${ }^{\mathrm{a}}$, Carita Savolainen-Kopra ${ }^{\mathrm{d}}$, Tarja Pitkänen ${ }^{\mathrm{a}, \mathrm{e}, *}$ \\ ${ }^{\text {a }}$ Finnish Institute for Health and Welfare, Expert Microbiology Unit, Kuopio, Finland \\ b Tampere University, Faculty of Medicine and Health Technology, Tampere, Finland \\ c Finnish Institute for Health and Welfare, Forensic Toxicology Unit, Helsinki, Finland \\ ${ }^{\mathrm{d}}$ Finnish Institute for Health and Welfare, Expert Microbiology Unit, Helsinki, Finland \\ e University of Helsinki, Faculty of Veterinary Medicine, Dept. Food Hygiene and Environmental Health, Finland
}

\section{H I G H L I G H T S}

- Wastewater sample aliquots during prolonged storage were investigated.

- SARS-CoV-2 RNA was detected for the first time in wastewater in Helsinki, Finland.

- SARS-CoV-2 RNA copy numbers were stable in cold temperatures over one to three months.

- SARS-CoV-2 RNA copy number declined over 28 days at $4{ }^{\circ} \mathrm{C}$ but not at $-20^{\circ} \mathrm{C}$ or $-75^{\circ} \mathrm{C}$.

- The inclusion of particulate matter should be considered in the analysis of SARS-COV RNA.
GRAPHICALABSTRACT

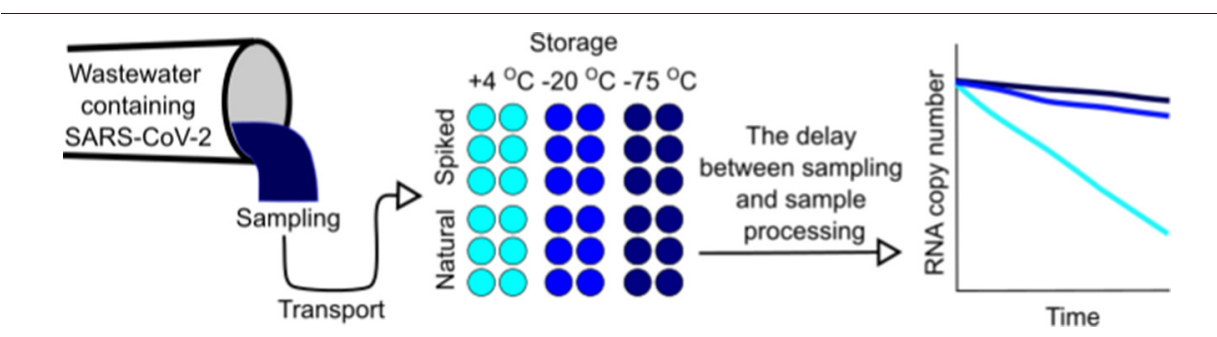

\section{A R T I C L E I N F O}

\section{Article history:}

Received 10 November 2020

Received in revised form 13 January 2021

Accepted 14 January 2021

Available online 21 January 2021

Editor: Damia Barcelo

\section{Keywords:}

Decay characteristics

New coronavirus

Municipal sewage

Storage conditions

\begin{abstract}
A B S T R A C T
Wastewater-based surveillance of the severe acute respiratory syndrome coronavirus 2 (SARS-CoV-2) is used to monitor the population-level prevalence of the COVID-19 disease. In many cases, due to lockdowns or analytical delays, the analysis of wastewater samples might only be possible after prolonged storage. In this study, the effect of storage conditions on the RNA copy numbers of the SARS-CoV-2 virus in wastewater influent was studied and compared to the persistence of norovirus over time at $4{ }^{\circ} \mathrm{C},-20^{\circ} \mathrm{C}$, and $-75^{\circ} \mathrm{C}$ using the reverse-transcription quantitative PCR (RT-qPCR) assays E-Sarbeco, N2, and norovirus GII. For the first time in Finland, the presence of SARS-CoV-2 RNA was tested in $24 \mathrm{~h}$ composite influent wastewater samples collected from Viikinmäki wastewater treatment plant, Helsinki, Finland. The detected and quantified SARS-CoV-2 RNA copy numbers of the wastewater sample aliquots taken during 19-20 April 2020 and stored for 29, 64, and 84 days remained surprisingly stable. In the stored samples, the SARS betacoronavirus and SARS-CoV-2 copy numbers, but not the norovirus GII copy numbers, seemed slightly higher when analyzed from the pre-centrifuged pellet-that is, the particulate matter of the influent-as compared with the supernatant (i.e., water fraction) used for ultrafiltration, although the difference was not statistically significant. Furthermore, when wastewater was spiked with SARS-CoV-2, linear decay at $4{ }^{\circ} \mathrm{C}$ was observed on the first 28 days, while no decay was visible within 58 days at $-20{ }^{\circ} \mathrm{C}$
\end{abstract}

\footnotetext{
* Corresponding author at: Finnish Institute for Health and Welfare, Expert Microbiology Unit, Kuopio, Finland.

E-mail address: tarja.pitkanen@thl.fi (T. Pitkänen).

${ }^{1}$ Current address: Finnish Food Authority, Laboratory and Research Division, Virology Unit, Helsinki, Finland.
} 
or $-75^{\circ} \mathrm{C}$. In conclusion, freezing temperatures should be used for storage when immediate SARS-CoV-2 RNA analysis from the wastewater influent is not possible. Analysis of the particulate matter of the sample, in addition to the water fraction, can improve the detection frequency.

(c) 2021 The Author(s). Published by Elsevier B.V. This is an open access article under the CC BY-NC-ND license (http://creativecommons.org/licenses/by-nc-nd/4.0/).

\section{Introduction}

Wastewater-based surveillance has been proposed for a rapid and resource-efficient way to monitor the population-level prevalence of severe acute respiratory syndrome coronavirus 2 (SARS-CoV-2), an etiological agent of the current global pandemic of coronavirus disease 2019 (COVID-19) (WHO, 2020; Ahmed et al., 2020a; Lodder and de Roda Husman, 2020; Mallapaty, 2020; Medema et al., 2020a; Orive et al., 2020). The wastewater-based approach can provide an effective way for identifying community-level hotspots of the infection and has been proposed as an early warning tool, providing extra time for actions to suppress the spread of infections before the availability of clinical surveillance information (La Rosa et al., 2021; Kitajima et al., 2020; Thompson et al., 2020). During the COVID-19 pandemic, the analytical capacities to study the SARS-CoV-2 RNA biomarkers from wastewater samples has been limited due to the laboratory and campus lockdowns at many locations with remote work recommendations. Furthermore, the lack of required methodological resources and validated methods, and delays in the deliveries of laboratory reagents and supplies (like the delayed availability of the plasticware required for ultrafiltration) due to global shortage, have hampered the immediate analysis of the SARS-CoV-2 RNA from the collected wastewater samples. Subsequently, on many occasions, researchers aiming to contribute to the fight against COVID-19 have been forced to store the collected samples and wait for the analytical resources to become available.

It has been claimed that the SARS-CoV-2 might have already circulated in many locations before the first reports from Wuhan, China, were received (Deslandes et al., 2020; La Rosa et al., 2021). Previously stored samples-like those of wastewater influents collected during the worldwide poliovirus monitoring (La Rosa et al., 2021; Hovi et al., 2012), together with stored respiratory samples from patients (Deslandes et al., 2020)-need to be analyzed to trace back to the first introduction of SARS-CoV-2 in different cities of the world. After the summer months of 2020, where the COVID-19 pandemic had a very slow or stagnant phase in countries like Finland, the resources for the quantitation of SARS-CoV-2 RNA from wastewater became more readily available. The analysis of stored samples might finally be possible in many locations, although not all bottlenecks to analysis availability have been tackled completely and the immediate actions required to tackle the next waves of the COVID-19 pandemic might again slow down the analysis of the previously stored samples.

It is important to determine the effect of storage conditions on the reliability of the SARS-CoV-2 RNA results as there is usually always a time lag between the sampling and the start of the laboratory examination due to the transportation and other logistical arrangements (Medema et al., 2020a). So far, the persistence of SARS-CoV-2 RNA in stored wastewater samples has only been studied at higher temperatures, $4{ }^{\circ} \mathrm{C}, 15^{\circ} \mathrm{C}, 25^{\circ} \mathrm{C}$, and $37^{\circ} \mathrm{C}$ (Ahmed et al., 2020b) and at $20^{\circ} \mathrm{C}$, $50{ }^{\circ} \mathrm{C}$, and $70{ }^{\circ} \mathrm{C}$ (Bivins et al., 2020). Furthermore, some stability information is obtained from other coronaviruses, like human coronavirus 229E (Gundy et al., 2008) and SARS-CoV-1 (Wang et al., 2005), or from surrogate organisms, such as murine hepatitis virus (MHV) (Casanova et al., 2009; Ye et al., 2016). This study aimed to establish the SARS-CoV-2 RNA stability characteristics in cold and freezing temperatures in order to evaluate the usability and reliability of the SARSCoV-2 RNA data gathered from previously collected and stored wastewater samples. To do this, we followed the decay of the SARS betacoronavirus envelope gene by using an E-Sarbeco RT-qPCR assay (Corman et al., 2020) and the decay of the SARS-CoV-2 nucleocapsid gene by using an N2 assay (Lu et al., 2020) in wastewater influent aliquots stored at $4{ }^{\circ} \mathrm{C},-20{ }^{\circ} \mathrm{C}$, and $-75^{\circ} \mathrm{C}$ over time. As a reference virus, the decay of norovirus genogroup II (GII), a non-enveloped human enteric virus known for its persistence in the environment (Kauppinen and Miettinen, 2017) and commonly found in municipal wastewater, was used. Further, this study also compared the detection of SARS-CoV-2 RNA copy numbers from the pre-centrifuged pelletsthat is, the particulate matter of the influent-with the supernatant (i.e., water fraction) used for ultrafiltration. This is the first study reporting the testing and detection of SARS-CoV-2 RNA from municipal wastewater in Finland.

\section{Materials and methods}

\subsection{Wastewater influent sampling and storage}

Table 1 shows the characteristics of the two wastewater influent samples collected from Viikinmäki wastewater treatment plant (WWTP), Helsinki, Finland. The Viikinmäki WWTP serves the population of 860,000 inhabitants from the municipalities of Helsinki, Sipoo, Kerava, Tuusula, Järvenpää, Pornainen, Mäntsälä, and Vantaa. Samples were collected from the influent before any treatment following the national guidance of biosafety precautions for WWTP personnel. Subsamples of $5000 \mathrm{ml}$ and $2000 \mathrm{ml}$ of 24-hour composite wastewater influent were collected from $6{ }^{\circ} \mathrm{C}$ refrigerated $20,000 \mathrm{ml}$ sample container during 19-20 April 2020 and 24-25 May 2020, respectively, and transported to the laboratory in cool boxes within $24-26 \mathrm{~h}$. Upon arrival to the laboratory, the samples were divided into $30 \mathrm{ml}$ aliquots and stored at temperatures of $4{ }^{\circ} \mathrm{C},-20^{\circ} \mathrm{C}$, and $-75^{\circ} \mathrm{C}$ for later analysis.

\subsection{The ultrafiltration method for the detection of SARS-COV-2 RNA in the stored samples}

For testing the presence and stability of SARS-CoV-2 RNA, triplicate aliquots of a single composite influent sample taken during 19-20 April 2020 was used. Frozen sample aliquots were thawed overnight at a temperature of $4{ }^{\circ} \mathrm{C}$ before analyses.

Prior to ultrafiltration performed after storage of samples for 29,64 , and 84 days, two $30 \mathrm{ml}$ aliquots were combined and larger particles were removed from triplicate $60 \mathrm{ml}$ influent samples with precentrifugation at $4654 \mathrm{~g}$ for $30 \mathrm{~min}$ without brake as previously described (Medema et al., 2020b). Then, the supernatants obtained (57-59 ml) were concentrated using Centricon Plus-70 centrifugal filters (a $10 \mathrm{~K}$ device, UFC701008, Millipore Corporation). Before use, the ultrafilters were washed with sterile deionized water, following the manufacturer's instructions. The ultrafiltration was conducted at $3000 \mathrm{~g}$ for $25 \mathrm{~min}$, followed by concentrate collection with $1000 \mathrm{~g}$ for $2 \mathrm{~min}$, producing approximately $400 \mu \mathrm{l}$ of concentrate.

In addition to the filtrated supernatant, the pellets from the suspended solids removal step (pre-centrifugation) were included into analysis soon after the importance of considering both liquid and solid fractions of wastewater samples when analyzing enveloped viruses such as SARS-CoV-2 had been realized (see, e.g., Ahmed et al., 2020c). The pellets were re-suspended into approximately $500 \mu \mathrm{l}$ of supernatant using widened pipette tip and analyzed from the samples after 84 days of storage. The concentrate volume was normalized to $700 \mu$ for all the filtrated supernatants and pre-centrifugation pellet samples by suspending them in the filtrate and supernatant, respectively. All treatment steps were carried out at room temperature. 
Table 1

The characteristics of the wastewater influent at Viikinmäki WWTP, Helsinki, Finland. The data obtained from the WWTP and the national infectious disease register.

\begin{tabular}{lll}
\hline Sampling time & From & From \\
& 19.4 .2020 & 24.5 .2020 \\
& $07: 00$ & $07: 00$ \\
& to 20.4 .2020 & to 25.5 .2020 \\
& $07: 00$ & $07: 00$ \\
\hline COVID-19 cases reported in the sewerage network & 1076 & 409 \\
area within the 14 days preceding the sampling & & \\
event & & \\
Total inflow during sampling $\left(\mathrm{m}^{3} / \mathrm{d}\right)$ & 306,019 & 251,741 \\
Composite sampling interval $\left(\mathrm{m}^{3}\right)$ & 18.8 & 18.8 \\
Influent temperature, ${ }^{\circ} \mathrm{C}(\mathrm{mean}$ min-max) & $12.0 ;$ & $13.3 ;$ \\
& $10.4-13.2$ & $12.4-14.2$ \\
$\mathrm{pH}$ & 7.4 & 7.4 \\
$\mathrm{BOD}(\mathrm{mg} / \mathrm{l})$ & 205 & 247 \\
$\mathrm{COD}(\mathrm{mg} / \mathrm{l})$ & 404 & 541 \\
$\mathrm{TSS}(\mathrm{mg} / \mathrm{l})$ & 204 & 302 \\
$\mathrm{~N}_{\text {tot }}(\mathrm{mg} / \mathrm{l})$ & 42 & 54 \\
$\mathrm{P}_{\text {tot }}(\mathrm{mg} / \mathrm{l})$ & 5.1 & 6.4 \\
$\mathrm{NH}_{4}-\mathrm{N}(\mathrm{mg} / \mathrm{l})$ & 32 & 35 \\
\hline
\end{tabular}

Abbreviations: BOD: biochemical oxygen demand; COD: chemical oxygen demand; TSS: total suspended solids; $\mathrm{N}_{\text {tot }}$ : total nitrogen concentration; $\mathrm{P}_{\text {tot }}$ : total phosphorus concentration; $\mathrm{NH}_{4}-\mathrm{N}$ : ammonium nitrate concentration.

Immediate nucleic acid extraction was conducted using $300 \mu$ of the final concentrated sample while the rest of the concentrate was preserved at $-75^{\circ} \mathrm{C}$ for later use.

The detection and quantitation of the viral targets entailed the determination of the copy numbers of SARS betacoronavirus with an ESarbeco assay (Corman et al., 2020) and of SARS-CoV-2 with an N2 assay (Medema et al., 2020b; Lu et al., 2020). Also, the copy numbers of norovirus GII (Kauppinen and Miettinen, 2017) were analyzed.

\subsection{The decay of SARS-CoV-2 RNA in wastewater stored at cold temperatures}

The decay characteristics of SARS-CoV-2 RNA were studied at the time points of $0,3,7,10,14$, and 21 days after the start of the experiment. Additionally, the effect of long-term storage was tested at $4{ }^{\circ} \mathrm{C}$ after 28 days and at $-20{ }^{\circ} \mathrm{C}$ and $-75{ }^{\circ} \mathrm{C}$ after 58 days. To reach sufficiently high copy numbers for the experiment, the influent sample taken during 24-25 May 2020 was spiked with a 1:1000 dilution of SARS-CoV-2 inoculum prepared from the nasopharyngeal swab of a COVID-19 patient. The produced spiked wastewater influent was divided into 57 microcentrifuge tubes in portions of $300 \mu l$. Triplicate tubes were stored in the dark at temperatures of $4{ }^{\circ} \mathrm{C},-20{ }^{\circ} \mathrm{C}$, and $-75^{\circ} \mathrm{C}$ and taken to direct nucleic acid extraction and subsequent reverse transcriptase-quantitative PCR (RT-qPCR) analysis. Frozen samples were thawed on ice before the analysis. The copy numbers of SARS betacoronavirus RNA were quantified with an E-Sarbeco assay. The specificity of the E-Sarbeco assay was confirmed by Sanger sequencing of the selected PCR products. The presence and quantitation of SARS-CoV-2 RNA in the sample material was confirmed using the $\mathrm{N} 2$ assay.

\subsection{Nucleic acid extraction and the RT-qPCR of the viral targets}

For nucleic acid extraction, a Chemagic Viral300 DNA/RNA extraction kit was used with a Chemagic-360D semi-automated nucleic acid extraction instrument (Perkin-Elmer, USA). For inactivation, $300 \mu \mathrm{l}$ of Lysis Buffer 1 and $300 \mu$ of the sample (concentrate or a re-suspended pre-centrifugation pellet) were mixed and incubated in room temperature for at least $10 \mathrm{~min}$. Poly(A) RNA and Proteinase $\mathrm{K}$ were added into the lysates and the extraction protocol was executed according to the manufacturer's instructions. Prior to downstream analysis, an additional purification of the nucleic acids extracted from the pre-centrifugation pellets was done using a OneStep ${ }^{\mathrm{TM}}$ PCR Inhibitor Removal Kit (Zymo Research, USA) according to the manufacturer's instructions.

The RT-qPCR assays were performed using TaqMan Fast Virus 1-step Master Mix and a QuantStudio 6 Flex real-time PCR system (Applied Biosystems, ThermoFisher Scientific). The primer and probe sequences are shown in Supplemental Table S1 and the reaction conditions in the Supplemental Table S2. In brief, all RT-qPCR reactions contained $5 \mu \mathrm{l}$ RNA sample in a final volume of $25 \mu \mathrm{l}$. For SARS betacoronavirus quantitation with an E-Sarbeco assay targeting envelope protein (Corman et al., 2020) and for norovirus GII quantitation (Kauppinen and Miettinen, 2017), RT-qPCR reactions contained $0.4 \mu \mathrm{M}$ primers and a $0.2 \mu \mathrm{M}$ probe. For SARS-CoV-2, an N2 assay targeting nucleocapsid protein (Medema et al., 2020b; Lu et al., 2020) was conducted in the same manner except that both primers and probe were used in a final concentration of $0.2 \mu \mathrm{M}$. The conditions were the same for the internal process control using mengovirus according to ISO/TC 15216-1:2013, except the final concentration of primers was $0.8 \mu \mathrm{M}$. For E-Sarbeco and $\mathrm{N} 2$ assays, the thermal cycling conditions were as follows: $50{ }^{\circ} \mathrm{C}$ for $5 \mathrm{~min}$ for reverse transcription, followed by $95^{\circ} \mathrm{C}$ for $20 \mathrm{~s}$, and then 45 cycles of $95^{\circ} \mathrm{C}$ for $15 \mathrm{~s}$ and $58^{\circ} \mathrm{C}$ for $1 \mathrm{~min}$. All the reactions considered positive exhibited $\mathrm{Ct}$ value below 40 . For norovirus GII and mengovirus, the thermal cycling conditions were the same except the annealing and extension was carried out in $60{ }^{\circ} \mathrm{C}$ instead of $58{ }^{\circ} \mathrm{C}$ (Supplemental Table S2).

For quantitation of the RT-qPCR targets, standard curves for each run were generated by using serial dilutions of control materials with a known quantity. In the E-Sarbeco assay and N2 assay, control plasmids pEX-A128-nCoV_E_Sarbeco (Eurofins, Luxembourg) and 2019_nCoV_N Positive Control (IDT, USA) were used, respectively. Before use, the pEXA128-nCoV_E_Sarbeco plasmid (100 ng $\mu^{-1}$ ) was digested with FastDigest NotI (ThermoScientific, USA) and purified using Illustra GFX PCR DNA and a Gel Band Purification Kit (GE Healthcare, UK) according to the manufacturer's instructions. For the N2 assay, the plasmid was used without linearization following the manufacturer's instructions. The quantitation of the norovirus GII assay was done using an artificial gene fragment (gBlocks, IDT).

\subsection{Confirmation of the SARS-CoV-2 target by sequencing}

The selected PCR products from E-Sarbeco assay were run by gel electrophoresis and approximately $113 \mathrm{bp}$ long bands were cut from the gel. The purification was done using a QIAquick Gel Extraction Kit (Qiagen, Germany) and, further, the sequencing was done in both directions by ABI BigDye ${ }^{\mathrm{TM}}$ v3.1 Chemistry (Applied Biosystems, USA) according to the manufacturer's protocol. The sequences were verified and aligned using Geneious 11.1.3 (Biomatters Ltd., New Zealand). The pair-end gene sequence of the E gene PCR product generated from a spiked wastewater sample was: ACTTCTTTTTCTTGCTTTCGTGGTATTCT TGCTAGTTACACTAGCCATCCTTACTGCGCTTCGAT. The consensus sequence was identified using BLAST analysis (https://blast.ncbi.nlm.nih. gov/Blast.cgi).

\subsection{Safety measures, quality assurance, and controls}

To ensure the safety of the laboratory work, wastewater and patient samples were processed as pair-work in a level 2 biosafety cabinet using cuffs, double gloves, and a laboratory coat. Only airtight sealed tubes were handled outside the biosafety cabinet. Seventy per cent ethanol was sprinkled on the outer surfaces of the tubes and airtight rotor lids and also used during the opening of the centrifuge lid after a one- to twominute waiting time following the centrifugation in order to prevent possible aerosols from entering into the air. To estimate the recovery efficiency of the ultrafiltration method, an enveloped virus control similar to SARS-CoV-2 was not available. Instead, a non-enveloped mengovirus was used as an internal process control following the principles of 
technical specification ISO/TS 15216-1:2013. Spiked mengovirus strain VMC0 (ATCC VR-1597, CeeramTOOLS, France) was used.

Each RNA extraction set included reagent blanks ( $300 \mu \mathrm{l}$ PBS or sterile deionized water) and a SARS-CoV-2 positive process control ( $300 \mu \mathrm{l}$ of 1:500 diluted nasopharyngeal swab sample from a COVID-19 positive patient, dissolved into PBS and inactivated at $60{ }^{\circ} \mathrm{C}$ for $90 \mathrm{~min}$ ). In RTqPCR, standard curves and no template controls were included in each run. RT-qPCR amplification efficiencies, as well as detection and quantification limits, are presented in Supplemental Table S3. The actual wastewater volume analyzed for each PCR assay (ml) was 3.8-4.0 ml for the authentic samples analyzed using the Centricon Plus-70 concentration method and $0.07 \mathrm{ml}$ in the inoculation experiment with direct extraction. Where possible, extracted RNA samples and their ten-fold dilutions were analyzed in duplicate. Ten-fold diluted samples were used to estimate the presence of inhibition: inhibition was considered significant if the gene copy number detected from the diluted sample was two times higher than the gene copy number detected from the undiluted sample. When applicable, the average results from both the diluted and undiluted sample were used to generate the final data.

\subsection{Statistics}

The viral RNA copy numbers were log-transformed into $\log _{10}$ before statistical analysis. The standard error with a 95\% confidence interval was calculated with the following formula:

SE $(\mathbf{9 5} \%$ Confidence Interval $)=\frac{\boldsymbol{\sigma}}{\sqrt{\mathbf{n}}} * t$,

where $\sigma$ is a standard deviation, $n$ is the number of samples, and $t$ is a critical value at the probability level of 0.025 (two-tailed) from a $t$ distribution table at ( $n-1)$ degrees of freedom.

The differences between the copy numbers in samples stored at the different temperatures were compared with the Kruskal-Wallis test followed with the Dunn post hoc test. The overlapping upper and lower confidence interval of mean copy numbers from E-Sarbeco and N2 assays generated from pellet and supernatant fractions were compared, as previously described (Tiwari et al., 2019).

The decay characteristics at the storage temperatures were analyzed with the GInaFiT Version 1.7 (Geeraerd and Van Impe Inactivation
Model Fitting Tool) freeware add-in for Microsoft $₫$ Office 365® Excel (Geeraerd et al., 2005), as done earlier (Tiwari et al., 2019; Han et al., 2020). GInaFiT is a commonly used tool for modeling the decay of microbes or their genetic markers. It tests nine different types of decay model, such as log-linear and biphasic models. In the GInaFiT tool, the regression analysis was performed $\left(\log _{10}\left(\mathrm{~N}_{\mathrm{t}}\right)\right.$ vs. time) for each viral target including the prediction of times needed for $90 \%$ and $99 \%$ reduction at the storage temperatures in the wastewater influent, as previously described by Casanova et al. (2009). Statistical analysis was done using IBM SPSS statistics.

\section{Results}

The SARS betacoronavirus, SARS-CoV-2, and norovirus GII RNA were detected from the wastewater sample collected during 19-20 April 2020 from the Viikinmäki WWTP, Helsinki, Finland. The quantity of SARS betacoronavirus and SARS-CoV-2 RNA when stored at $4{ }^{\circ} \mathrm{C}$, $-20^{\circ} \mathrm{C}$, and $-75^{\circ} \mathrm{C}$ and analyzed with E-Sarbeco and $\mathrm{N} 2$ assays, respectively, remained stable at all storage temperatures for up to 84 days (Table 2). At the same time, norovirus GII RNA copy numbers reduced about $1-\log _{10}$ during the time interval between 29 and 84 days of storage (Table 2). The copy numbers of SARS betacoronavirus and SARS-CoV-2 RNA were slightly more frequently quantified with a higher total mean from the pellet fraction of the samples stored for 84 days, that is, the particulate matter from the pre-centrifugation step, rather than from ultrafiltrated supernatant fraction (Table 2, E-Sarbeco and N2 assays). At the same time, with a non-enveloped virus type, norovirus GII, used as a different reference to enveloped SARS and SARS-CoV-2 viruses, the target mean difference in the quantified copy numbers between the pellet and supernatant fractions was the opposite.

The obtained recovery efficiencies for the mengovirus process control varied from $17.5 \%$ to $100.5 \%$ in supernatant fractions and were considered sufficient (Supplemental Table S3). Mengovirus is also a non-enveloped virus and was added to the samples just prior the ultrafiltration. The range of mengovirus recovery rates from precentrifugation pellets was $0.4 \%-5.3 \%$ (Supplemental Table S3). Although we used an additional purification of the nucleic acids extracted from the pre-centrifugation pellets prior RT-qPCR, this step might not be essential and the need depends on the sample and extraction kit properties in use in each laboratory.

Table 2

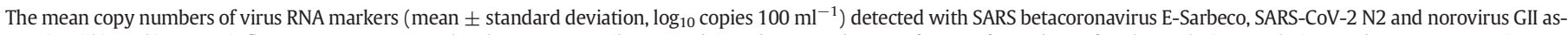

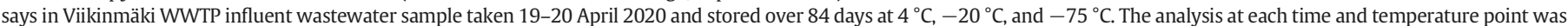
performed from triplicate aliquots. The number of replicates with results above the quantification limit (LOQ) are shown in parenthesis.

\begin{tabular}{|c|c|c|c|c|c|c|}
\hline \multirow[t]{2}{*}{ Target } & \multirow[t]{2}{*}{ Sample fraction } & \multirow[t]{2}{*}{ Storage time (days) } & \multicolumn{3}{|c|}{ RNA copy number at storage temperatures } & \multirow[t]{2}{*}{ Quantification frequency (number of aliquots) } \\
\hline & & & $4{ }^{\circ} \mathrm{C}$ & $-20{ }^{\circ} \mathrm{C}$ & $-75^{\circ} \mathrm{C}$ & \\
\hline \multirow[t]{6}{*}{ SARS E-Sarbeco } & \multirow[t]{3}{*}{ Supernatant } & 29 & $2.6 \pm 0.2(2)$ & $<\operatorname{LOQ}(0)$ & $2.4(1)$ & \\
\hline & & 64 & $3.1 \pm 0.2(3)$ & $2.8 \pm 0.2(3)$ & $2.8 \pm 0.0(2)$ & \\
\hline & & 84 & $2.9 \pm 0.3(2)$ & $2.5(1)$ & $2.8 \pm 0.3(2)$ & \\
\hline & \multicolumn{5}{|c|}{ Total mean $\pm S E(95 \% C I): 2.8 \pm 0.1$} & Supernatant: 16/27 (59\%) \\
\hline & Pellet $^{\mathrm{a}}$ & 84 & $3.4 \pm 0.2(3)$ & $2.8 \pm 0.5(2)$ & $3.3 \pm 0.0(2)$ & \\
\hline & \multicolumn{5}{|c|}{ Total mean $\pm S E(95 \% C I): 3.2 \pm 0.2$} & Pellet: 7/9 (78\%) \\
\hline \multirow[t]{6}{*}{ SARS-CoV-2 N2 } & \multirow[t]{3}{*}{ Supernatant } & 29 & $3.7 \pm 0.1(2)$ & $3.5(1)$ & $3.6 \pm 0.1(2)$ & \\
\hline & & 64 & $3.7 \pm 0.2(3)$ & $3.7 \pm 0.1(2)$ & $3.7 \pm 0.1(2)$ & \\
\hline & & 84 & $3.7 \pm 0.2(2)$ & $3.4(1)$ & $3.6 \pm 0.2(3)$ & \\
\hline & \multicolumn{5}{|c|}{ Total mean $\pm S E(95 \% C I): 3.6 \pm 0.1$} & Supernatant: 18/27 (67\%) \\
\hline & Pellet $^{\mathrm{a}}$ & 84 & $4.2 \pm 0.1(3)$ & $3.9 \pm 0.1(2)$ & $3.9 \pm 0.4(3)$ & \\
\hline & \multicolumn{5}{|c|}{ Total mean $\pm S E(95 \% C I): 4.0 \pm 0.2$} & Pellet: 8/9 (89\%) \\
\hline \multirow[t]{6}{*}{ Norovirus GII } & \multirow[t]{3}{*}{ Supernatant } & 29 & $4.4 \pm 0.2(3)$ & $4.8 \pm 0.1(3)$ & $4.8 \pm 0.1(3)$ & \\
\hline & & 64 & $3.7 \pm 0.1(3)$ & $3.7 \pm 0.1(3)$ & $3.8 \pm 0.0(3)$ & \\
\hline & & 84 & $3.5 \pm 0.1(3)$ & $3.6 \pm 0.3(3)$ & $3.7 \pm 0.1(3)$ & \\
\hline & \multicolumn{5}{|c|}{ Total mean $\pm S E(95 \% C I): 4.0 \pm 0.2$} & Supernatant: 27/27 (100\%) \\
\hline & Pellet $^{\mathrm{a}}$ & 84 & $3.8 \pm 0.2(3)$ & $3.0 \pm 0.1(2)$ & $3.0 \pm 0.1(3)$ & \\
\hline & \multicolumn{5}{|c|}{ Total mean $\pm S E(95 \% C I): 3.3 \pm 0.3$} & Pellet: 8/9 (89\%) \\
\hline
\end{tabular}

\footnotetext{
a The analysis is performed for the particulate fraction (i.e., pellets from pre-centrifugation). $\mathrm{SE}=$ standard error, $\mathrm{CI}=$ confidence interval.
} 
The copy numbers from days $0-28$ remained unknown for the sample taken 19-20 April 2020 (Table 2) since during that time the method for the immediate analysis of the viral biomarkers from influent samples was not available. Therefore, a Viikinmäki WWTP influent wastewater sample taken five weeks later, during 24-25 May 2020, was used to experimentally characterize the decay rate of SARS-CoV-2 RNA copy numbers during the first month of the cold storage of wastewater. Before spiking, the sample contained the target RNA of the levels 3.1 and 3.8 $\log _{10}$ copies $100 \mathrm{ml}^{-1}$ when analyzed using E-Sarbeco and N2 assays, respectively. After a spike with a nasopharyngeal swab from a COVID19 patient, the copy numbers of the RNA targets in the beginning of the experiment reached the level of 7.4 and $8.1 \log _{10}$ copies $100 \mathrm{ml}^{-1}$ in E-Sarbeco and N2 assays, respectively.

When the E-Sarbeco assay was used, no statistically significant difference between the storage temperatures was noted (Fig. 1, $p=$ 0.258 , Kruskal-Wallis), although after two weeks of storage and thereafter, the sample aliquots stored at freezing temperatures $\left(-20{ }^{\circ} \mathrm{C}\right.$ and $-75{ }^{\circ} \mathrm{C}$ ) seemed to produce higher quantities than refrigeration $\left(4^{\circ} \mathrm{C}\right)$. When the $\mathrm{N} 2$ assay was used, a statistically significant difference between the storage temperatures was observed (Fig. 1, $p=0.039$, Kruskal-Wallis). A linear decay of SARS-CoV-2 RNA was observed at $4{ }^{\circ} \mathrm{C}$ while no decay was visible within 58 days at the freezing temperatures of $-20^{\circ} \mathrm{C}$ and $-75^{\circ} \mathrm{C}$ (Fig. 1). Regression analysis, calculated with GInaFiT, was done for the sample aliquots stored at $4{ }^{\circ} \mathrm{C}$ (Table 3 ). The decay was more linear and slightly faster when $\mathrm{N} 2$ was used as a target $\left(R^{2}=0.99\right)$ when compared to E-Sarbeco assay results $\left(R^{2}=0.59\right)$.

\section{Discussion}

This is the first study reporting the detection of SARS-CoV-2 RNA in wastewater influent in Finland. The presence of the biomarkers of SARSCoV-2 in wastewater influent samples collected during April and May 2020 from Viikinmäki WWTP, Helsinki, Finland, is in agreement with the national infectious disease register data regarding the confirmed COVID-19 cases in the municipalities of the Viikinmäki WWTP sewerage network area preceding the sampling and with studies conducted earlier in other countries (e.g., Ahmed et al., 2020a; Haramoto et al., 2020; La Rosa et al., 2020a; Medema et al., 2020b; Mlejnkova et al.,
Table 3

The decay characteristics of the SARS-CoV-2 spike $\left(\log _{10}\right.$ copies $\left.100 \mathrm{ml}^{-1}\right)$ in wastewater influent at $4{ }^{\circ} \mathrm{C}$, enumerated with E-Sarbeco and N2 assays. Samples stored at $-20{ }^{\circ} \mathrm{C}$ and $-75^{\circ} \mathrm{C}$ were not suitable for decay modeling as no decay was observed.

\begin{tabular}{lllllll}
\hline Assay & $\begin{array}{l}\text { Decay rate } \\
(\mathrm{k})\end{array}$ & $R^{2}$ & $\begin{array}{l}\text { Square } \\
\text { difference }\end{array}$ & $\begin{array}{l}T_{50} \\
\text { (days) }\end{array}$ & $\begin{array}{l}T_{90} \\
\text { (days) }\end{array}$ & $\begin{array}{l}T_{99} \\
\text { (days) }\end{array}$ \\
\hline E-Sarbeco & $0.04 \pm 0.2$ & 0.59 & 0.15 & 16 & 52 & 105 \\
N2 & $0.06 \pm 0.0$ & 0.99 & 0.00 & 11 & 36 & 73 \\
\hline
\end{tabular}

2020; Arora et al., 2020). In the sample aliquots stored at $4{ }^{\circ} \mathrm{C},-20^{\circ} \mathrm{C}$, and $-75^{\circ} \mathrm{C}$ and analyzed after storage herein, the SARS-CoV-2 RNA seemed surprisingly stable in these cold storage temperatures from 29 days to 64 and 84 days prior to carrying out the sample concentration and nucleic acid extraction. Further, the results generated by spiking the wastewater influent matrix with a diluted nasopharyngeal swab sample from a COVID-19 patient and following the RNA signal from experiment initiation (day 0 ) to 28 and 58 days in refrigerated and freezing conditions, respectively, confirmed the stability of SARS-CoV-2 RNA, especially when stored in freezing temperatures.

A limitation of the study set-up was that we were not able to follow SARS-CoV-2 copy numbers during the first 28 days of storage using the real wastewater samples. Instead, we conducted a separate spike-in study to reveal the decay characteristics between 0 and 28 days. The conventional route of transmission of SARS betacoronaviruses is via respiratory droplets passing through the nasopharynx. A nasopharyngeal swab sample was used herein in order to gain high enough quantities of SARS-CoV-2 for the spike-in experiment. However, the survival kinetics of SARS-CoV-2 after passage through the gastrointestinal tract and, furthermore, after the transport of the viral particles-first in the sewerage system to the WWTP and then in a sample container to the laboratorymight be different than those of a highly contagious nasopharyngeal sample. While the finding of viral RNA in stools or wastewater does not imply that the virus is viable and infectious (Foladori et al., 2020), the two experiments carried out herein (the analysis of actual wastewater samples after storage and the spike-in study) both indicated the stability of the RNA signal during storage in freezing temperatures. Therefore, this study has assumed the decay characteristics of the RNA
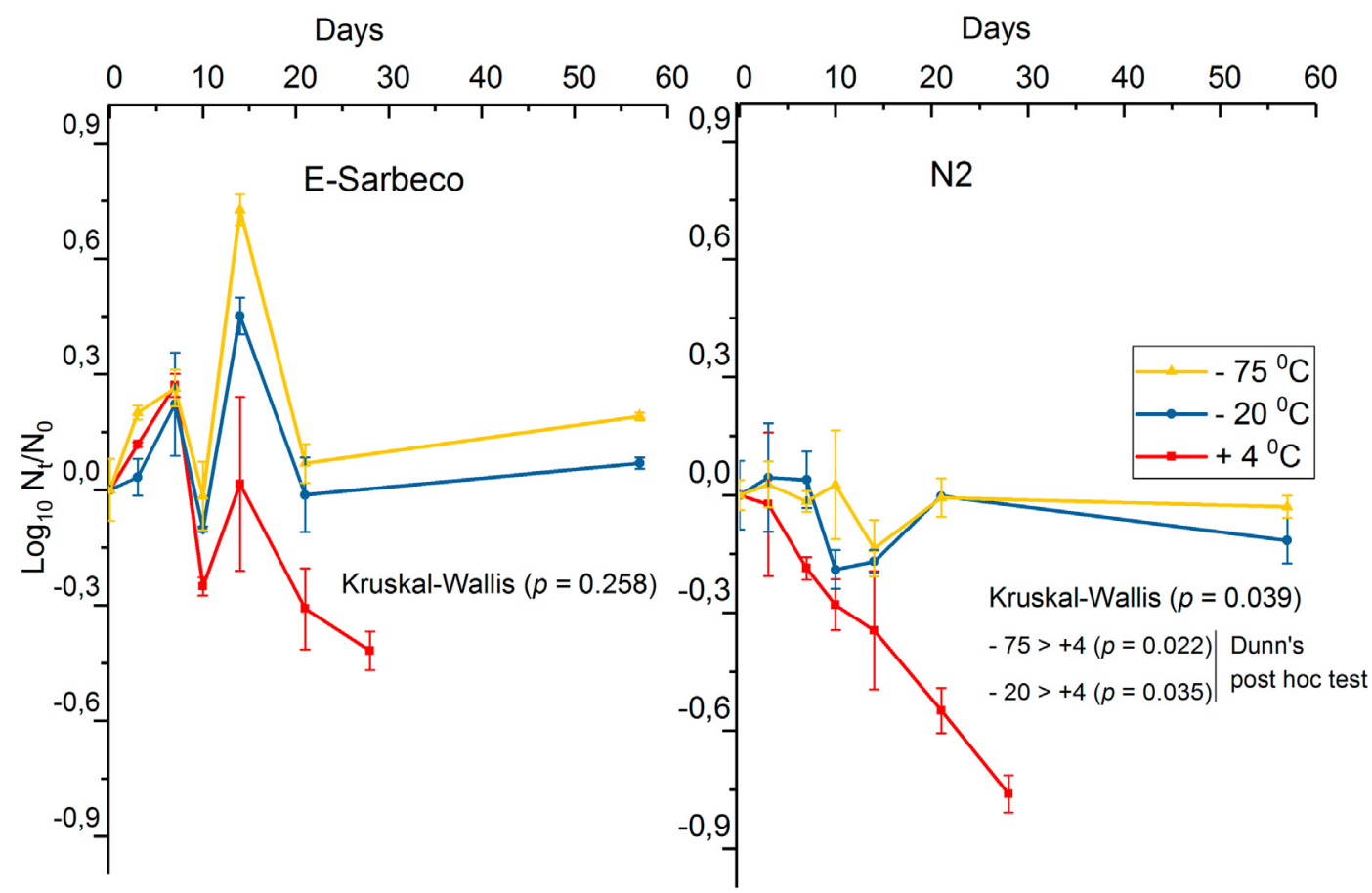

Fig. 1. The decay curve of SARS-CoV-2 spike ( $\log _{10}$ copies $100 \mathrm{ml}^{-1}$ ) in wastewater influent at $4{ }^{\circ} \mathrm{C},-20^{\circ} \mathrm{C}$, and $-75^{\circ} \mathrm{C}$, enumerated with E-Sarbeco and N2 RT-qPCR assays. 
from fresh virus particles from COVID-19 patient may not differ from virus RNA from wastewater samples. The wastewater system represents virus particles that have ended up there from the fecal materials, urine, coughing, sneezing, and sputum of infected people, with the majority of virus particles possibly originating from feces (WHO, 2020).

While the viruses previously analyzed by environmental microbiologists are most commonly non-enveloped viruses-such as poliovirus, norovirus, adenovirus, or enterovirus-SARS-CoV-2 is an enveloped virus. Currently, the protocols for SARS-CoV-2 testing from wastewater samples vary a lot despite the multiple efforts to harmonize the virus concentration and quantitation approaches (Hill et al., 2020; Kitajima et al., 2020; Kordatou et al., 2020). As the aim is to detect the virus at low concentrations in wastewater, the efficiency of the procedures employed for sampling, preserving, and processing samples are critical (Medema et al., 2020a) and there is a need for developing standardized and reliable virus quantification protocols (Orive et al., 2020).

Interestingly, while the SARS-CoV-2 RNA remained almost stable at $4{ }^{\circ} \mathrm{C},-20^{\circ} \mathrm{C}$, and $-75^{\circ} \mathrm{C}$ when the wastewater influent was stored up to 84 days, norovirus reduced by about $1 \log _{10}$ value during the same time. This observation indicates that (actually against the current belief; Hill et al., 2020) the persistency of non-enveloped viruses is not necessarily higher than the persistence of enveloped viruses in cold environmental conditions. Based on previous reports, it is known that coronaviruses decline rapidly at ambient temperatures in wastewater (Ahmed et al., 2020b; Gundy et al., 2008; La Rosa et al., 2020b; Silverman and Boehm, 2020). Wang et al. (2005) recovered SARS$\mathrm{CoV}-1$ after at least 14 days in wastewater stored at $4{ }^{\circ} \mathrm{C}$ while they reported it surviving only two days at $20^{\circ} \mathrm{C}$. Ye et al. (2016) concluded that, with MHV surrogate, the inactivation kinetics of the enveloped viruses are significantly slower in wastewater at $10^{\circ} \mathrm{C}$ compared to $25^{\circ} \mathrm{C}$. Previously, with surrogate coronaviruses, transmissible gastroenteritis, and MHV, Casanova et al. (2009) concluded that at $4{ }^{\circ} \mathrm{C}$ there was a $<1 \log _{10}$ infectivity decrease for both viruses after four weeks. More recently, Ahmed et al. (2020b) reported that, by using an N1 gene target for SARS-CoV-2 RNA in untreated wastewater, the mean first-order decay rate constant $(k)$ for SARS-CoV-2 was $0.084 /$ day at $4{ }^{\circ} \mathrm{C}$. In the present study, SARS-CoV-2 RNA copy numbers exhibited a linear decay with a $k$ value of 0.04 and 0.06 for $\mathrm{N} 2$ and E-Sarbeco gene targets in wastewater, respectively, over 21 days when stored at $4{ }^{\circ} \mathrm{C}$. On the contrary, the RNA count in Viikinmäki WWTP influent remained unchanged over 58 days in the wastewater influent stored at $-20^{\circ} \mathrm{C}$ and $-75^{\circ} \mathrm{C}$. Overall, the inactivation of coronaviruses in the wastewater seems highly dependent on temperature. However, between the samples and sampling locations, the level of organic matter, and the presence of other microbes could affect the persistence.

Of the two biomarker assays for SARS-CoV-2 employed herein, the SARS-CoV-2 RNA quantified using the N2 assay exhibited a slightly higher decay rate than the SARS betacoronavirus RNA copy numbers obtained using the E-Sarbeco assay. The slightly more rapid decay of the N2 assay target compared with the E-Sarbeco assay target may indicate the differential decay rates of nucleocapsid and envelope genes (Mousavizadeh and Ghasemi, 2020). More information is needed on the stability of different marker genes used for wastewater-based SARS-CoV-2 surveillance. Overall, the information about the fate of enveloped viruses in municipal wastewater has been scarce. When Ye et al. (2016) studied the survival and partitioning behavior of model viruses in raw wastewater samples, up to $26 \%$ of the enveloped MHV and Pseudomonas phage $\phi 6$ viruses adsorbed to the solid fraction of wastewater compared with $6 \%$ of the non-enveloped bacteriophages (MS2 and T3). Although more research is needed, SARS-CoV-2 in WWTP influent could also be associated with the particulate fraction of the sample.

It is noteworthy that the ultrafiltration method commonly used for wastewater SARS-CoV-2 RNA analysis includes a pre-centrifugation step, wherein part of the particulate fraction is removed from the analysis (Medema et al., 2020b). Such an approach might not be optimal for enveloped viruses such as SARS-CoV-2, as was recently shown in a MHV surrogate study where concentration methods using both liquid and solid fractions of wastewater produced the best yields (Ahmed et al., 2020c). When we used the ultrafiltration method for the Viikinmäki WWTP samples stored for 84 days at $4{ }^{\circ} \mathrm{C},-20^{\circ} \mathrm{C}$, and $-75^{\circ} \mathrm{C}$, the quantification frequency and the quantities of SARS-CoV-2 RNA biomarkers were slightly higher when analyzed from pre-centrifuged pellets rather than from the water fraction without the particulate matter. From the same samples, the quantification frequency and the copy numbers of the norovirus RNA were on average higher when analyzed from supernatants when compared with pellets. The finding may indicate the higher affinity of an enveloped virus like SARS-CoV-2 to attach onto the particulate matter of wastewater when compared with nonenveloped viruses like norovirus. Indeed, instead of only studying wastewater influent, research groups have recently reported SARSCoV-2 RNA detection in sewage sludge, proposing that the sludge could serve as a better indicator for COVID-19 outbreak dynamics than WWTP influent (Kocamemi et al., 2020; Peccia et al., 2020).

\section{Conclusions}

- SARS-CoV-2 RNA was detected for the first time in the $24 \mathrm{~h}$ composite influent wastewater sample collected from Viikinmäki WWTP, Helsinki, Finland, during 19-20 April 2020.

- The SARS-CoV-2 RNA remained detectable during storage periods of 29,64 , and 84 days at $4{ }^{\circ} \mathrm{C},-20{ }^{\circ} \mathrm{C}$, and $-75{ }^{\circ} \mathrm{C}$ when analyzed using E-Sarbeco and N2 RT-qPCR assays.

- The SARS-CoV-2 RNA quantification frequency and copy numbers were slightly higher when the particulate matter of the influent was analyzed, compared with the pre-centrifuged supernatant fraction used for ultrafiltration.

- In the sample pre-treatment procedures for ultrafiltration, the pellet from the initial larger particle removal step should not be discarded when the samples are analyzed after long-term storage. In the analysis of fresh wastewater samples, the necessity to also analyze the pellet should be further investigated.

- A linear decay of spiked SARS-CoV-2 RNA was observed at $4{ }^{\circ} \mathrm{C}$ while no decay was visible within 58 days at the freezing temperatures. In cases when immediate SARS-CoV-2 RNA analysis from the wastewater influent is not possible, storage at $-20^{\circ} \mathrm{C}$ or $-75^{\circ} \mathrm{C}$ should be preferred.

\section{CRediT authorship contribution statement}

Anna-Maria Hokajärvi: Conceptualization, Investigation, Writing review \& editing, Formal analysis. Annastiina Rytkönen: Investigation, Writing - original draft. Ananda Tiwari: Investigation, Writing original draft, Formal analysis. Ari Kauppinen: Conceptualization, Investigation, Writing - review \& editing. Sami Oikarinen: Investigation, Writing - review \& editing. Kirsi-Maarit Lehto: Funding acquisition, Writing - review \& editing, Resources. Aino Kankaanpää: Investigation, Writing - review \& editing. Teemu Gunnar: Funding acquisition, Writing - review \& editing, Resources. Haider Al-Hello: Supervision, Writing - review \& editing. Soile Blomqvist: Supervision, Writing - review \& editing. Ilkka T. Miettinen: Writing - review \& editing, Resources. Carita Savolainen-Kopra: Funding acquisition, Supervision, Writing - review \& editing, Resources. Tarja Pitkänen: Conceptualization, Funding acquisition, Supervision, Investigation, Writing - original draft, Writing - review \& editing, Formal analysis, Resources.

\section{Declaration of competing interest}

The authors declare that they have no known competing financial interests or personal relationships that could have influenced the work reported in this paper. 


\section{Acknowledgements}

The authors would like to express special thanks to the personnel of Helsinki Region Environmental Services Authority HSY and Director Mari Heinonen at the HSY Wastewater Services Department for their support during the project's establishment and WWTP sampling arrangements. The personnel of the Health Security Department at the Finnish Institute for Health and Welfare are acknowledged with special thanks given to Oskari Luomala and Riikka Airaksinen for their help with the communicable disease statistics and to Tiina Heiskanen, Marjo Tiittanen, Tarja Rahkonen and Arja Moilanen for their assistance in the laboratory. This study was supported by Finnish Government supplementary budget for Covid-19 research and the Ministry of Agriculture and Forestry (grant number 4400T-0807).

\section{Appendix A. Supplementary data}

Supplementary data to this article can be found online at https://doi. org/10.1016/j.scitotenv.2021.145274.

\section{References}

Ahmed, W., Angel, N., Edson, J., Bibby, K., Bivins, A., O’Brien, J.W., Choi, P.M., Kitajima, M., Simpson, S.L., Li, J., Tscharke, B., Verhagen, R., Smith, W.J.M., Zaugg, J., Dierens, L., Hugenholtz, P., Thomas, K.V., Mueller, J.F., 2020a. First confirmed detection of SARS$\mathrm{CoV}-2$ in untreated wastewater in Australia: a proof of concept for the wastewater surveillance of COVID-19 in the community. Sci. Total Environ. 728, 138764. https://doi.org/10.1016/j.scitotenv.2020.138764.

Ahmed, W., Bertsch, P.M., Bibby, K., Haramoto, E., Hewitt, J., Huygens, F., Gyawali, P., Korajkic, A., Riddell, S., Sherchan, S.P., Simpson, S.L., Sirikanchana, K., Symonds, E.M., Verhagen, R., Vasan, S.S., Kitajima, M., Bivins, A., 2020b. Decay of SARS-CoV-2 and surrogate murine hepatitis virus RNA in untreated wastewater to inform application in wastewater-based epidemiology. Environ. Res. 2020, 110092. https://doi.org/ 10.1016/j.envres.2020.110092.

Ahmed, W., Bertsch, P.M., Bivins, A., Bibby, K., Farkas, K., Gathercole, A., Haramoto, E., Gyawali, P., Korajkic, A., McMinn, B.R., Mueller, J.F., Simpson, S.L., Smith, W.J.M., Symonds, E.M., Thomas, K.V., Verhagen, R., Kitajima, M., 2020c. Comparison of virus concentration methods for the RT-qPCR-based recovery of murine hepatitis virus, a surrogate for SARS-CoV-2 from untreated wastewater. Sci. Total Environ. 739, 139960. https://doi.org/10.1016/j.scitotenv.2020.139960.

Arora, S., Nag, A., Sethi, J., Rajvanshi, J., Saxena, S., Shrivastava, S.K., Gupta, A.B., 2020. Sewage surveillance for the presence of SARS-CoV-2 genome as a useful wastewater based epidemiology (WBE) tracking tool in India. medRxiv (preprint). https://doi. org/10.1101/2020.06.18.20135277.thi.

Bivins, A., Greaves, J., Fischer, R., Yinda, K.C., Ahmed, W., Kitajima, M., Munster, V.J., Bibby, K., 2020. Persistence of SARS-CoV-2 in water and wastewater. Environ. Sci. Technol. Lett. 7 (12), 937-942. https://doi.org/10.1021/acs.estlett.0c00730.

Casanova, L., Rutala, W.A., Weber, D.J., Sobsey, M.D., 2009. Survival of surrogate coronaviruses in water. Water Res. 43 (7), 1893-1898. https://doi.org/10.1016/j. watres.2009.02.002.

Corman, V.M., Landt, O., Kaiser, M., Molenkamp, R., Meijer, A., Chu, D.K.W., Bleicker, T., Brünink, S., Schneider, J., Schmidt, M.L., Mulders, D.G.J.C., Haagmans, B.L., van der Veer, B., van den Brink, S., Wijsman, L., Goderski, G., Romette, J.-L., Ellis, J., Zambon, M., Peiris, M., Goossens, H., Reusken, C., Koopmans, M.P.G., Drosten, C., 2020. Detection of 2019 novel coronavirus (2019-nCoV) by real-time RT-PCR. Euro Surveill. 25 (3), 2000045. https://doi.org/10.2807/1560-7917.ES.2020.25.3.2000045.

Deslandes, A., Berti, V., Tandjaoui-Lambotte, Y., Alloui, C., Carbonnelle, E., Zahar, J.R., Brichler, S., Cohen, Y., 2020. SARS-CoV-2 was already spreading in France in late December 2019. Int. J. Antimicrob. Agents 55 (6), 106006. https://doi.org/10.1016/j. ijantimicag.2020.106006.

Foladori, P., Cutrupi, F., Segata, N., Manara, S., Pinto, F., Malpei, F., Bruni, L., La Rosa, G., 2020. SARS-CoV-2 from faeces to wastewater treatment: what do we know? A review. Sci. Total Environ. 743, 140444. https://doi.org/10.1016/j.scitotenv.2020.140444.

Geeraerd, A.H., Valdramidis, V.P., van Impe, J.F., 2005. GInaFiT, a freeware to assess nonlog-linear microbial survivor curves. Int. J. Food Microbiol. 102 (1), 95-105. https:// doi.org/10.1016/j.ijfoodmicro.2004.11.038.

Gundy, P.M., Gerba, C.P., Pepper, I.L., 2008. Survival of coronaviruses in water and wastewater. Food Environ. Virol. 1 (1), 10. https://doi.org/10.1007/s12560-008-9001-6.

Han, Z., Huang, G., Liao, J., Li, J., Lyu, G., Ma, J., 2020. Disentangling survival of Escherichia coli 0157:H7 in soils: from a subpopulation perspective. Sci. Total Environ. 749, 141649 (Doi:1016/j.scitotenv.2020.141649).

Haramoto, E., Malla, B., Thakali, O., Kitajima, M., 2020. First environmental surveillance for the presence of SARS-CoV-2 RNA in wastewater and river water in Japan. Sci. Total Environ. 737, 140405. https://doi.org/10.1016/j.scitotenv.2020.140405.

Hill, K., Zamyadi, A., Deere, D., Vanrolleghem, P.A., Crosbie, N., 2020. SARS-CoV-2 known and unknowns, implications for the water sector and wastewater-based epidemiology to support national responses worldwide: early review of global experiences with the COVID-19 pandemic. Water Qual Res J. https://doi.org/10.2166/ wqrj.2020.100.

Hovi, T., Shulman, L.M., van der Avoort, H., Deshpande, J., Roivainen, M., de Gourville, E.M., 2012. Role of environmental poliovirus surveillance in global polio eradication and beyond. Epidemiol. Infect. 140, 1-13. https://doi.org/10.1017/S095026881000316X.

Kauppinen, A., Miettinen, I.T., 2017. Persistence of norovirus GII genome in drinking water and wastewater at different temperatures. Pathogens 6 (4), 48. https://doi.org/ 10.3390/pathogens6040048

Kitajima, M., Ahmed, W., Bibby, K., Carducci, A., Gerba, C.P., Hamilton, K.A., Haramoto, E., Rose, J.B., 2020. SARS-CoV-2 in wastewater: state of the knowledge and research needs. Sci. Total Environ. 739, 139076. https://doi.org/10.1016/.scitotenv.2020.139076.

Kocamemi, B.A., Kurt, H., Sait, A., Sarac, F., Saatci, A.M., Pakdemirli, B., 2020. SARS-CoV-2 detection in Istanbul wastewater treatment plant sludges. medRxiv (preprint). https://doi.org/10.1101/2020.05.12.20099358.t.

Kordatou, M., Karaolia, P., Fatta-Kassinos, D., 2020. Sewage analysis as a tool for the COVID-19 pandemic response and management: the urgent need for optimised protocols for SARS-CoV-2 detection and quantification. J. Environ. Chem. Eng. 8, 104306. https://doi.org/10.1016/j.jece.2020.104306.

La Rosa, G., Iaconelli, M., Mancini, P., Ferraro, G.B., Veneri, C., Bonadonna, L., Lucentini, L., Suffredini, E., 2020a. First detection of SARS-CoV-2 in untreated wastewaters in Italy. Sci. Total Environ. 736, 139652. https://doi.org/10.1016/j.scitotenv.2020.139652.

La Rosa, G., Bonadonna, L., Lucentini, L., Kenmoe, S., Suffredini, E., 2020b. Coronavirus in water environments: occurrence, persistence and concentration methods - a scoping review. Water Res. 179, 115899. https://doi.org/10.1016/j.watres.2020.115899.

La Rosa, G., Mancini, P., Ferraro, G.B., Veneri, C., Iaconelli, M., Bonadonna, L., Lucentini, L., Suffredini, E., 2021. SARS-CoV-2 has been circulating in northern Italy since December 2019: evidence from environmental monitoring. Sci. Total Environ. 750, 141711. https://doi.org/10.1016/j.scitotenv.2020.141711.

Lodder, W., de Roda Husman, A.M., 2020. SARS-CoV-2 in wastewater: potential health risk, but also data source. Lancet Gastroenterol. Hepatol. 5 (6), 533-534. https://doi. org/10.1016/S2468-1253(20)30087-X.

Lu, X., Wang, L., Sakthivel, S.K., Whitaker, B., Murray, J., Kamili, S., Lynch, B., Malapati, L. Burke, S.A., Harcourt, J., Tamin, A., Thornburg, N.J., Villanueva, J.M., Lindstrom, S., 2020. US CDC real-time reverse transcription PCR panel for detection of severe acute respiratory syndrome coronavirus 2. Emerg. Infect. Dis. 26 (8), 1654-1665. https://doi.org/10.3201/eid2608.201246.

Mallapaty, S., 2020. How sewage could reveal true scale of coronavirus outbreak. Nature 580 (7802), 176-177. https://doi.org/10.1038/d41586-020-00973-X.

Medema, G., Been, F., Heijnen, L., Petterson, S., 2020a. Implementation of environmental surveillance for SARS-CoV-2 virus to support public health decisions: opportunities and challenges. Curr. Opin. Environ. Sustain. 17, 49-71. https://doi.org/10.1016/j. coesh.2020.09.006.

Medema, G., Heijnen, L., Elsinga, G., Italiaander, R., Brouwer, A., 2020b. Presence of SARSCoronavirus-2 RNA in sewage and correlation with reported COVID-19 prevalence in the early stage of the epidemic in The Netherlands. Environ. Sci. Technol. Lett. 7 (7), 511-516. https://doi.org/10.1021/acs.estlett.0c00357.

Mlejnkova, H., Sovova, K., Vasickova, P., Ocenaskova, V., Jasikova, L., Juranova, E., 2020. Preliminary study of SARS-CoV-2 occurrence in wastewater in the Czech Republic. Int. J. Environ. Res. Public Health 17, 5508.

Mousavizadeh, L., Ghasemi, S., 2020. Genotype and phenotype of COVID-19: their roles in pathogenesis. J Microbiol Immunol Infect. https://doi.org/10.1016/j.jmii.2020.03.022.

Orive, G., Lertxundi, U., Barcelo, D., 2020. Early SARS-CoV-2 outbreak detection by sewage-based epidemiology. Sci. Total Environ. 732 (25), 139298. https://doi.org/ 10.1016/j.scitotenv.2020.139298.

Peccia, J., Zulli, A., Brackney, D.E., Grubaugh, N.D., Kaplan, E.H., Casanovas-Massana, A., Ko, A.I., Malik, A.A., Wang, D., Wang, M., Warren, J.L., Weinberger, D.M., Omer, S.B., 2020. SARS-CoV-2 RNA concentrations in primary municipal sewage sludge as a leading indicator of COVID-19 outbreak dynamics. medRxiv (preprint). Doi:https://doi.org/ 10.1101/2020.05.19.20105999.t.

Silverman, A.I., Boehm, A.B., 2020. Systematic review and meta-analysis of the persistence and disinfection of human coronaviruses and their viral surrogates in water and wastewater. Environ. Sci. Technol. Lett. 7 (8), 544-553. https://doi.org/10.1021/acs. estlett.0c00313.

Thompson, J.R., Nancharaiah, Y.V., Gu, X., Lee, W.L., Rajal, V.B., Haines, M.B., Girones, R., Ng, L.C., Alm, E.J., Wuertz, S., 2020. Making waves: wastewater surveillance of SARS-CoV2 for population-based health management. Water Res. 184, 116181. https://doi.org/ 10.1016/j.watres.2020.116181.

Tiwari, A., Kauppinen, A., Pitkänen, T., 2019. Decay of Enterococcus faecalis, Vibrio cholerae and MS2 coliphage in a laboratory mesocosm under brackish beach conditions. Front. Public Health 7, 269. https://doi.org/10.3389/fpubh.2019.00269.

Wang, X.W., Li, J.S., Jin, M., Zhen, B., Kong, Q.X., Song, N., Xiao, W.J., Yin, J., Wei, W., Wang, G.J., Si, B.Y., Guo, B.Z., Liu, C., Ou, G.R., Wang, M.N., Fang, T.Y., Chao, F.H., Li, J.W., 2005. Study on the resistance of severe acute respiratory syndrome-associated coronavirus. J. Virol. Methods 126 (1-2), 171-177. https://doi.org/10.1016/j.jviromet.2005.02.005

WHO, 2020. Status of environmental surveillance for SARS-CoV-2 virus. Scientific brief, 5 August 2020. World Health Organisation. WHO/2019-nCoV/Sci_Brief/ EnvironmentalSampling/2020.1.

Ye, Y., Ellenberg, R.M., Graham, K.E., Wigginton, K.R., 2016. Survivability, partitioning, and recovery of enveloped viruses in untreated municipal wastewater. Environ. Sci. Technol. 50 (10), 5077-5085. https://doi.org/10.1021/acs.est.6b00876. 